\title{
The lateral infratrigeminal transpontine window to deep pontine lesions
}

\author{
*Paolo Ferroli, MD, ${ }^{1}$ Marco Schiariti, MD, ${ }^{1}$ Roberto Cordella, PhD, ${ }^{1}$ Carlo Boffano, MD, ${ }^{2}$ \\ Simone Nava, MSc, ${ }^{2}$ Emanuele La Corte, MS, ${ }^{1}$ Claudio Cavallo, MS, ${ }^{1}$ Dario Bauer, MD, ${ }^{3}$ \\ Melina Castiglione, MD, ${ }^{1}$ Morgan Broggi, MD, PhD, ${ }^{1}$ Francesco Acerbi, MD, PhD, ${ }^{1}$ and \\ Giovanni Broggi, MD1
}

1Departments of Neurosurgery and 2Neuroradiology, Fondazione IRCCS Istituto Neurologico "Carlo Besta"; and "Unit of Human Pathology, Department of Health Sciences, San Paolo Hospital Medical School, University of Milano, Milan, Italy

OBJECT Surgery of brainstem lesions is increasingly performed despite the fact that surgical indications and techniques continue to be debated. The deep pons, in particular, continues to be a critical area in which the specific risks related to different surgical strategies continue to be examined. With the intention of bringing new knowledge into this important arena, the authors systematically examined the results of brainstem surgeries that have been performed through the lateral infratrigeminal transpontine window.

METHODS Between 1990 and 2013, 29 consecutive patients underwent surgery through this window for either biopsy sampling or for removal of a deep pontine lesion. All of this work was performed at the Department of Neurosurgery of the Istituto Nazionale Neurologico "Carlo Besta", in Milan, Italy. A retrospective analysis of the findings was conducted with the intention of bringing further clarity to this important surgical strategy.

RESULTS The lateral infratrigeminal transpontine window was exposed through 4 different approaches: 1) classic retrosigmoid (15 cases), 2) minimally invasive keyhole retrosigmoid (10 cases), 3) translabyrinthine (1 case), and 4) combined petrosal ( 3 cases). No deaths occurred during the entire clinical study. The surgical complications that were observed included hydrocephalus ( 2 cases) and CSF leakage (1 case). In 6 (20.7\%) of 29 patients the authors encountered new neurological deficits during the immediate postoperative period. All 6 of these patients had undergone lesion removal. In only 2 of these 6 patients were permanent sequelae observed at 3 months follow-up. These findings show that $93 \%$ of the patients studied did not report any permanent worsening of their neurological condition after this surgical intervention.

CONCLUSIONS This retrospective study supports the idea that the lateral infratrigeminal transpontine window is both a low-risk and safe corridor for either biopsy sampling or for removal of deep pontine lesions.

http://thejns.org/doi/abs/10.3171/2014.11.JNS141116

KEY WORDS brainstem; lateral approach; transpontine approach; pons; fiber tractography; diagnostic and operative techniques

$\mathrm{S}$ URGERY of intraaxial brainstem lesions has been shown to be feasible and is now being performed in selected patients despite the risk of functional brainstem damage. $., 15,20,31$ There are many variables that affect the results of this surgery such as patient selection, surgical techniques, and available technologies. In addition, there is currently no consensus surrounding the decision-making process that guides the surgeon to choose this approach. This is particularly true when this surgery is under consideration for deep pontine lesions that require a brainstem incision to be exposed. In fact, the pons remains one of the most protected and inaccessible areas of the brain because its exposition is obstructed by the cerebellum posteriorly, by the petrous bone laterally, and by septic nasal cavities

ABBREVIATIONS CMAP = compound muscle action potential; $\mathrm{CN}$ = cranial nerve; DTI = diffusion tensor imaging; $\mathrm{GTR}$ = gross-total resection; MEP = motor evoked potential; $\mathrm{mRS}=$ modified Rankin Scale; SSEP = somatosensory evoked potential; STR = subtotal resection.

SUBMITTED May 19, 2014. ACCEPTED November 7, 2014.

INCLUDE WHEN CITING Published online June 12, 2015; DOI: 10.3171/2014.11.JNS141116.

DISCLOSURE The authors report no conflict of interest concerning the materials or methods used in this study or the findings specified in this paper.

${ }^{*}$ Drs. Ferroli and Schiariti contributed equally to this work. 
and the clivus anteriorly. In addition, access to the deep pons is limited by the tegmentum pontis containing cranial nerve $(\mathrm{CN})$ nuclei and substantia reticulata nuclei posteriorly, and by corticospinal tracts and perforating arteries anteriorly. Further complicating matters are the transverse pontine fibers, which are directed to the middle cerebellar peduncle and that border the lateral surface of the pons. As early as $1982,{ }^{2}$ some authors had used the lateral approach to the pons for lesion biopsy with a low rate of complications. Despite this report, in the following years the relatively easy surgical accessibility of the floor of the fourth ventricle induced many authors to use and study this route to the deep pons, and relatively "safe" entry zones were identified. ${ }^{4,20,34}$ More recently, the need to further reduce the impact of surgical sequelae affecting a patient's quality of life and the refinement of neurophysiological monitoring has pushed some groups to explore and develop lateral alternative approaches to the deep pons..$^{10,15,17,25}$

Given these historical considerations, this study focused attention on the technical aspects and results of surgery for deep pontine lesions when approached through the lateral infratrigeminal window.

\section{Methods}

Surgeries performed through the lateral infratrigeminal transpontine window for the purposes of biopsy sampling or removing a deep pontine lesion were conducted in 29 consecutive patients at the Department of Neurosurgery of the Istituto Nazionale Neurologico "Carlo Besta" between January 1, 1990, and January 31, 2013. The study population included both sexes, with ages ranging from 3 to 67 years old (mean 38.5 years old). The baseline clinical and surgical data obtained on these 29 patients are summarized in Table 1: age; sex; symptoms; preoperative neurological examination; histological diagnosis; surgical approach; preoperative, early, and 3-month postoperative modified Rankin scale (mRS) score; complications and results at 3 months follow-up; postoperative MRI evaluation of resection grade; and follow-up duration. The results from some of these patients have already been analyzed and described in a previous paper regarding brainstem cavernous angiomas. ${ }^{10}$ In this report we have continued to evaluate the clinical data, operative records, and radiological findings of this larger series. These results have been collected and analyzed, retrospectively, by independent reviewers (M.S., E.L.C., and C.C., i.e., not the operating surgeons) with the aid and assistance of a dedicated neuroradiologist (C.B.).

The mRS score was used to provide an objective measurement to define the preoperative clinical status as well as the early and 3-month postoperative clinical status of these patients. ${ }^{28}$

\section{Presurgical Diagnostic Workup}

The presurgical diagnostic workup that was performed on all of the patients described in this study included a preoperative neurological examination, axial CT scans, and multiplanar MR images obtained with a contrast medium injection. At later stages of this study we began to use some new techniques that have been more recently developed, such as diffusion tensor imaging (DTI; Fig. 1) for the study of the intrapontine course of the corticospinal tract and CNs. In 1 patient, angiography was also included as part of the diagnostic investigation. This added procedure was performed when a non-angiographically occult vascular malformation was suspected.

Somatosensory evoked potentials (SSEPs), brainstem auditory evoked potentials, $\mathrm{CN}$ muscle electromyography, and audiovestibular examination were also used to further investigate patients who presented with some clinical evidence of brainstem dysfunction. A CSF examination was never required in any of the patients in this study.

\section{Surgical Planning and Pertinent Anatomy}

None of the 29 lesions were found to abut the brainstem surface. For lesions that were found to be ventral to the lemniscal plane (Fig. 2), the choice of the lateral route was made for obvious reasons. In fact, the high concentration of delicate and fundamental anatomofunctional structures in the dorsal portion of the brainstem, along with the ventral position of the corticospinal system, makes the lateral route ideal when it comes to avoiding the most vulnerable pontine areas (Fig. 2, "labyrinth of cranial nerve nuclei/fibers"). Nuclei and fibers of the substantia reticularis also contribute to the complexity of the tegmental pontine region largely because of sensory, motor, and vegetative functions, many of which are still only incompletely known. This is especially the case when it comes to the delicate balance among neurotransmitters and modulators, much of which remains outside the realm of any meaningful neurophysiological monitoring.

Additional safety reasons to use the lateral route arise from the constant presence of an almost avascular area in the infratrigeminal lateral pontine region and from the good working space between the trigeminal nerve and $\mathrm{CN}$ VII-VIII complex (Fig. 3). For the group of lesions that primarily involved the tegmental region of the pons, the choice of this lateral route was somewhat less obvious and we have chosen a case to illustrate this particular surgical scenario (see illustrative case below).

\section{Surgical Technique and Different Approaches}

The infratrigeminal lateral pontine region between the origin of CN V and the course of the CN VII-VIII complex was exposed through different approaches such as the classic retrosigmoid (15 cases), minimally invasive keyhole retrosigmoid (10 cases), translabyrinthine (1 case), and combined petrosal approaches (3 cases). After 1995, neuronavigation has been used in the great majority of the cases.

The choice of the surgical approach started with the analysis of the lesion's shape, anatomical relationships, volume, and position, followed by the application of Spetzler's "two-point method." ${ }^{26}$ This method helps define the best surgical trajectory to optimally address the lesion. Briefly, the line drawn between the center of the lesion and its most superficial point, and extended toward the cranial surface, estimates the ideal site for the bone opening. Different methods of 3D virtual planning have been used in the last 3 years to facilitate this process. ${ }^{11,12}$ The decision of whether to use a posterior, posterolateral, lateral, or anterolateral approach was thus made, also taking into con- 


\section{过

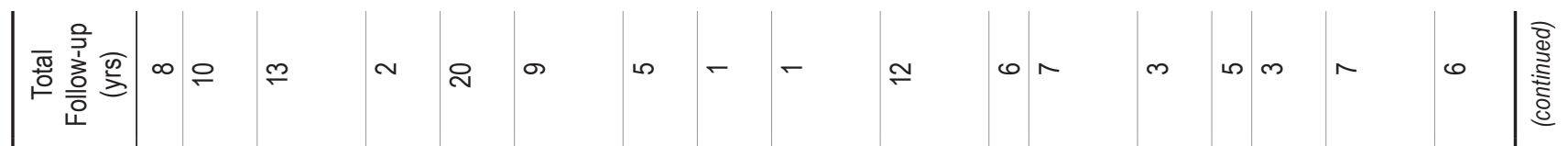

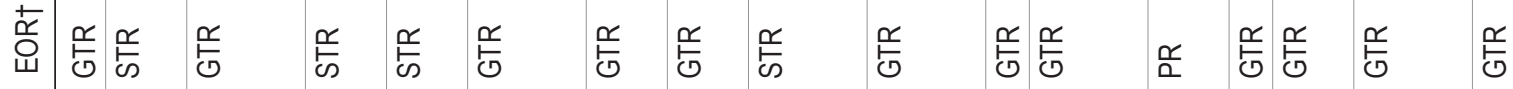
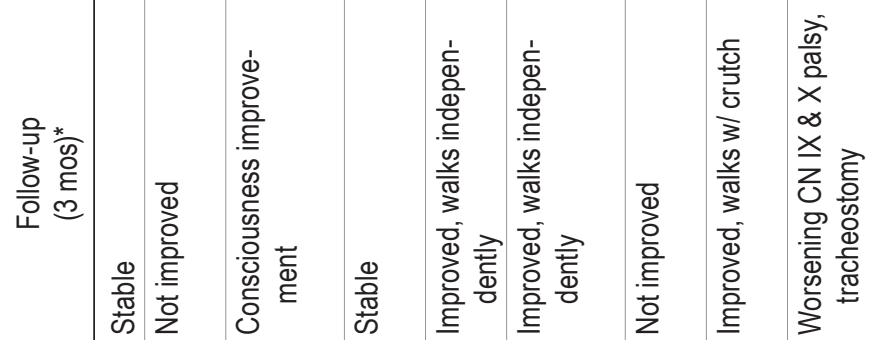

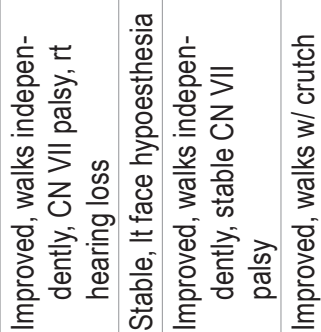
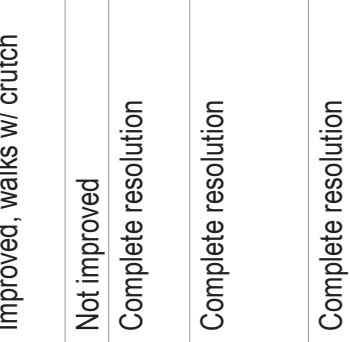

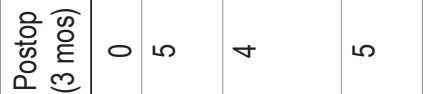
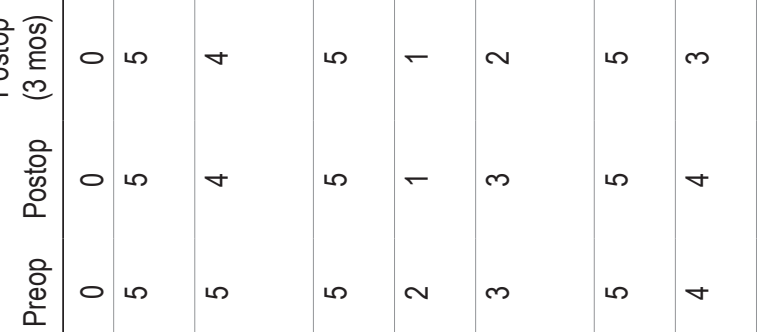

을

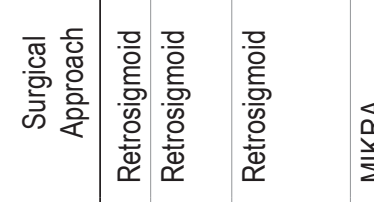
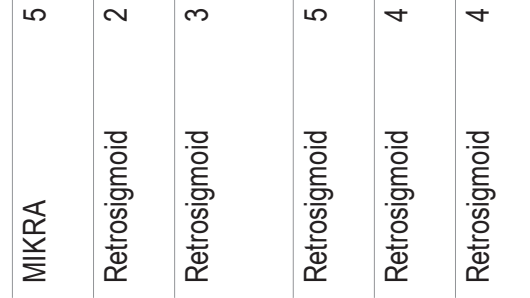

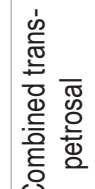
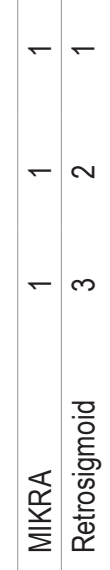

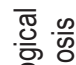

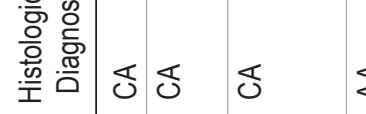

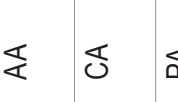

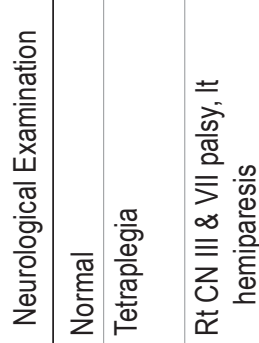

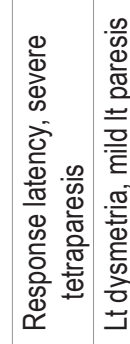

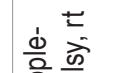

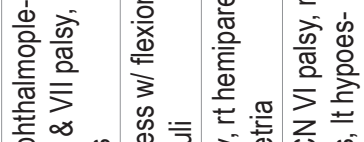

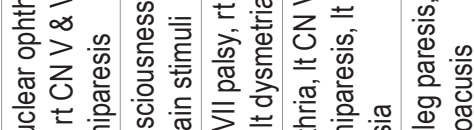

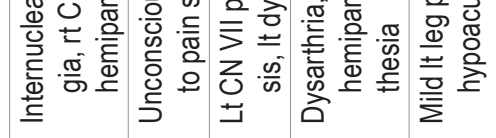

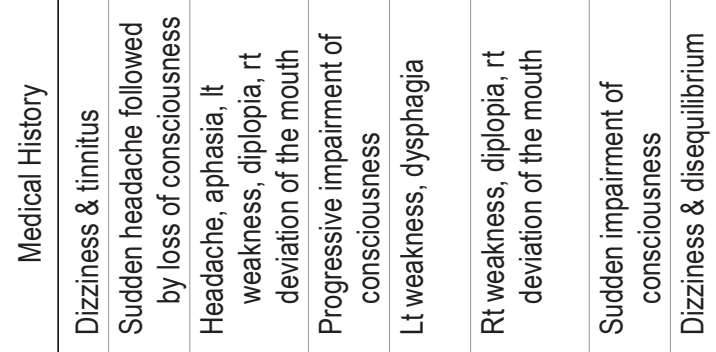

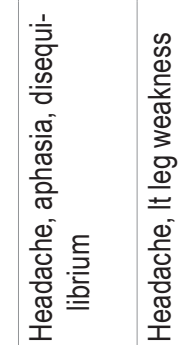

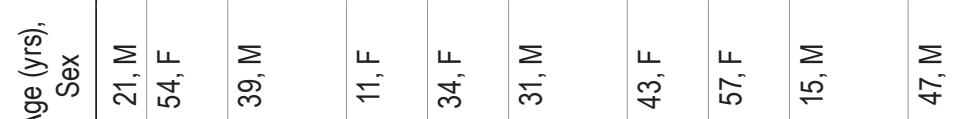

禹 这

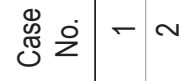

m

$\checkmark \quad \infty$

$\bullet$

$\wedge \infty$

a

으

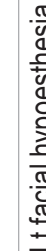

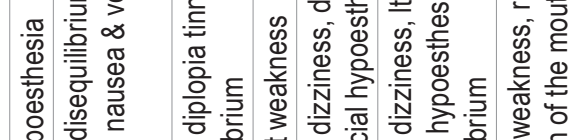

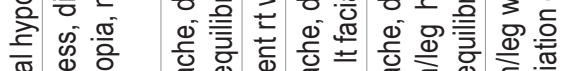

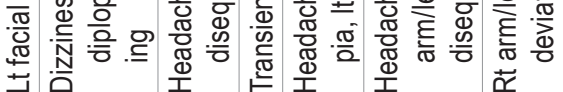

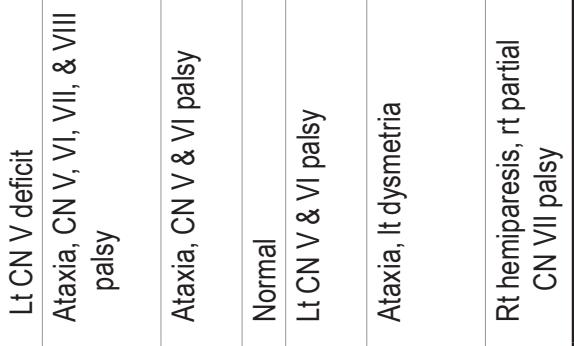

in $\quad$ is $\frac{0}{2}$

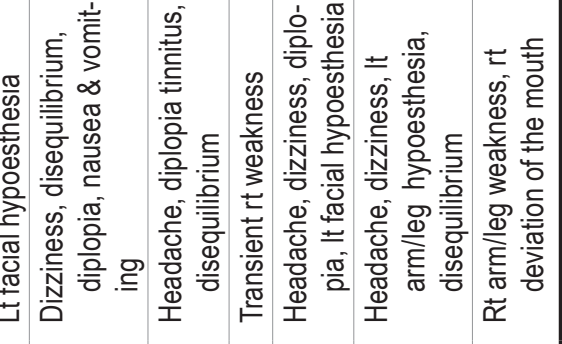

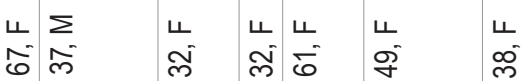

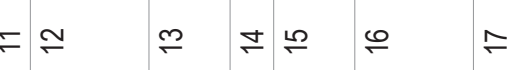




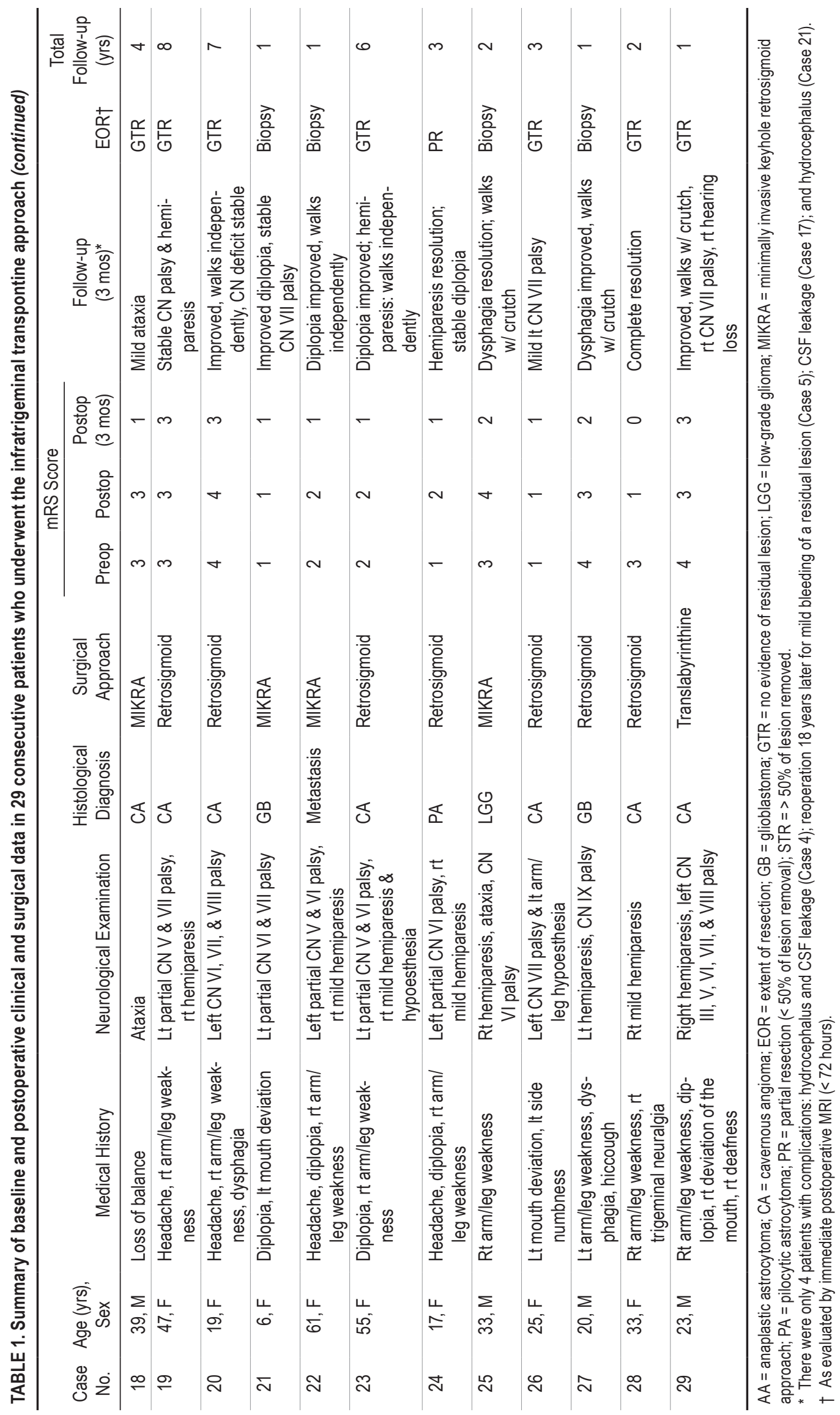




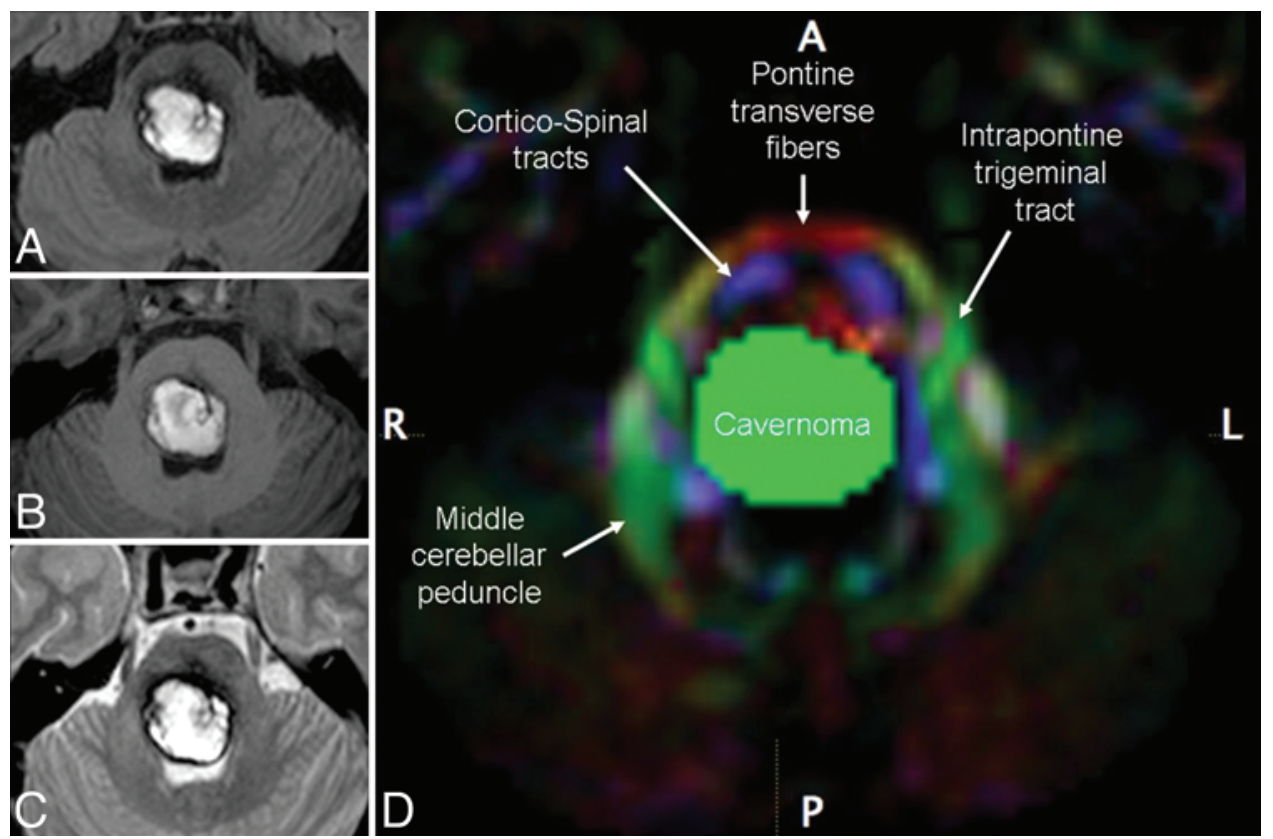

FIG. 1. Case 29. A-C: Axial FLAIR (A), T1-weighted with Gd (B), and T2-weighted (C) MR images of a brainstem cavernoma. D: DTI-based, directionally encoded color map of the same patient. $A=$ anterior; $P=$ posterior.

sideration the direction of the main axis of the lesion and the relative light provided by each different approach over the most delicate and dangerous dissection areas. A minimally invasive keyhole retrosigmoid approach was generally used for lesion biopsies or resection of small lesions. When a wider resection of a big lesion was planned, larger approaches were favored. Tailored petrous-bone drilling, with or without the addition of a subtemporal transtentorial route, was considered when deemed useful to provide additional light to otherwise hidden tumor-brainstem eloquent and delicate interfaces.

Lateral approaches provided a good exposure of the whole lateral brainstem surface from the fourth to the eleventh $\mathrm{CN}$. When needed, the transverse cerebellar fissure was opened to further increase and optimize the lateral pontine surface exposure at the level of the infratrigeminal region. The pons was incised along the course of transverse pontine fibers in the infratrigeminal region between the V and the VII-VIII CNs, where an avascular surface suitable for pial incision was always present (Fig. 4).

According to the surgeon's preference, the supine position (with the head rotated on the opposite side) or the semisitting position was mainly used. In particular cases the so-called "park-bench" position and the lateral position

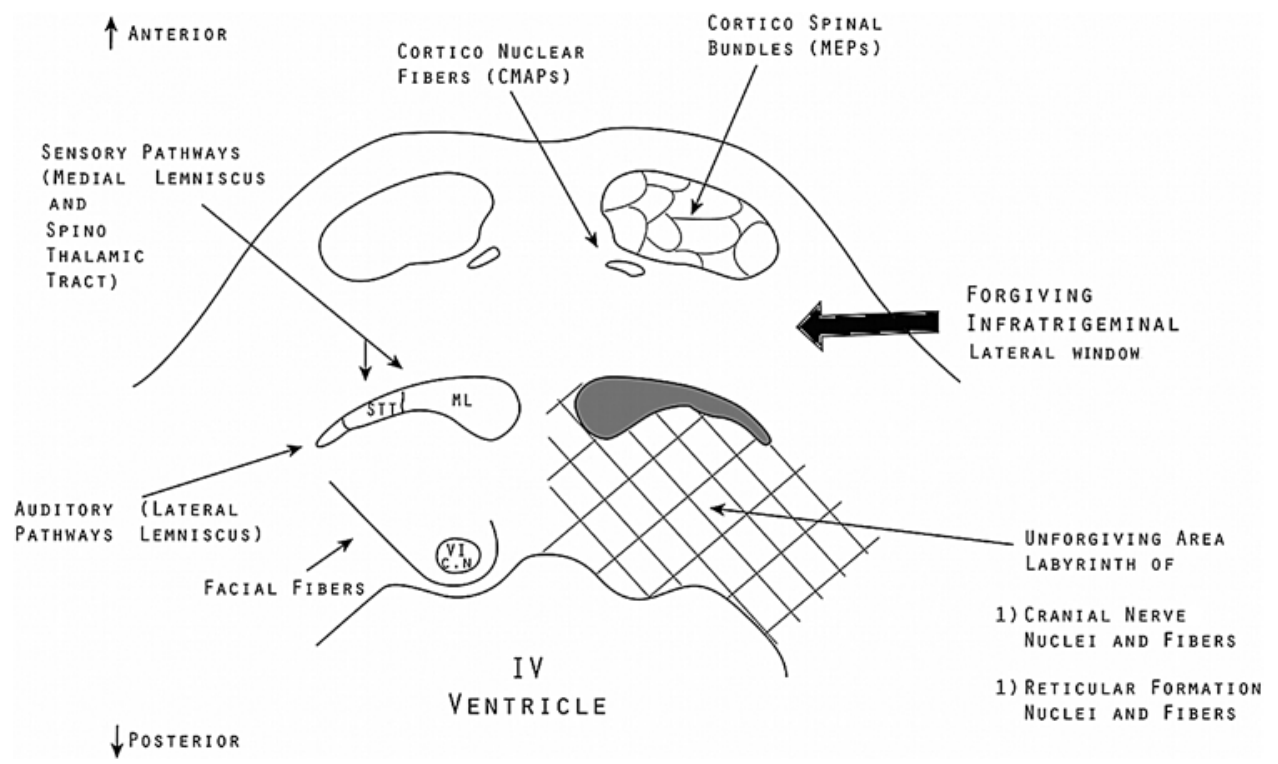

FIG. 2. Schematic representation of a midpons infratrigeminal pontine section. $M L=$ medial lemniscus; $S T T=$ spinothalamic tract. 


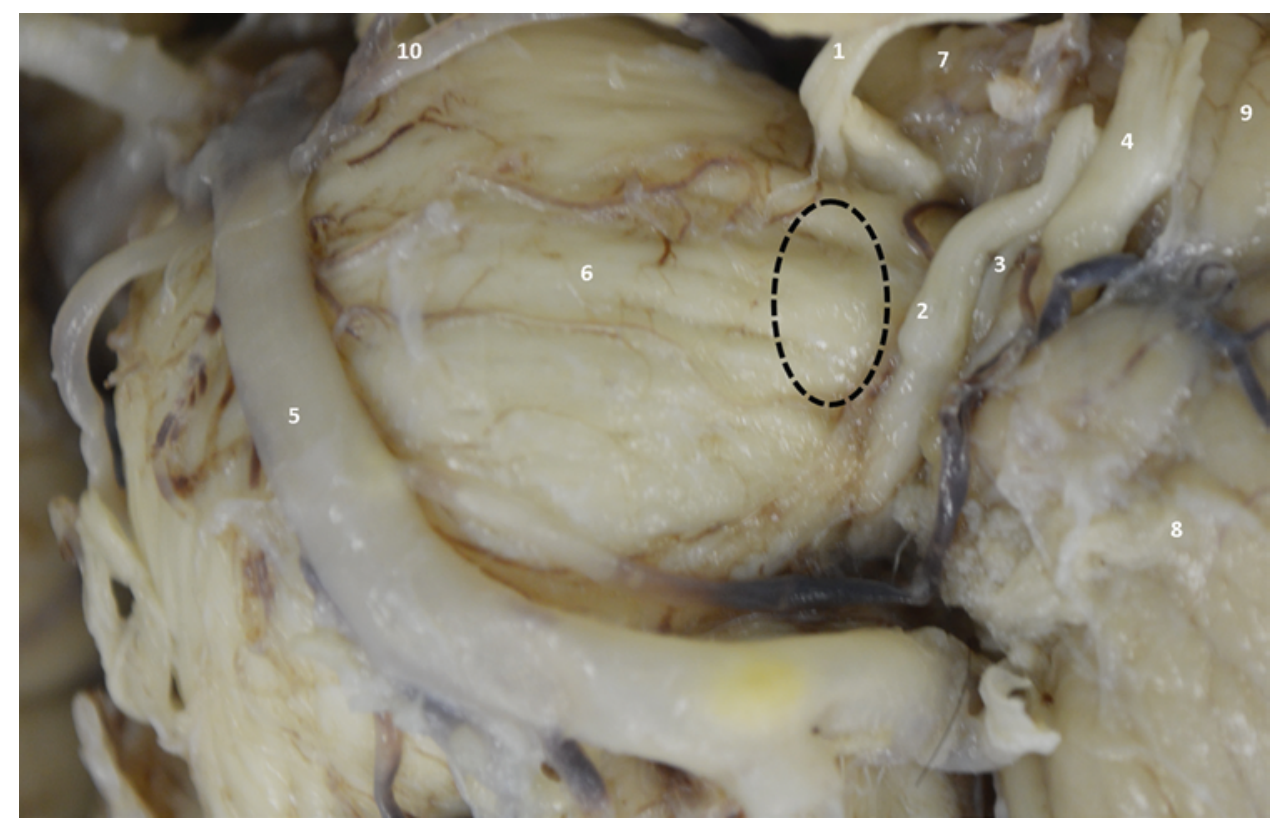

FIG. 3. Left anterolateral view of the brainstem. The dashed oval represents the infratrigeminal lateral pontine window. This area is located between the emergences of the CN V and the CN VII and VIII complexes. 1 = trigeminal nerve; $2=$ facial nerve; $3=$ Wrisberg's intermedius nerve; $4=$ vestibular nerve; $5=$ basilar artery; $6=$ pons; $7=$ choroid plexus; $8=$ cerebellum; $9=$ flocculus; $10=$ left superior cerebellar artery.

were also adopted. In the case of the semisitting position, a complete cardiological evaluation was always used in the preoperative anesthesiological workup. This evaluation included transesophageal echocardiography or transcranial Doppler ultrasound with injection of air microbubbles so as to allow for the detection of possible right-to-left heart shunts.

Since the early days of the 21st century, the use of selfretaining retractors has been almost completely abandoned so as to avoid the risks of overstretching and/or overcompression. The gentle application of cerebellar spatulas was only used in the semisitting position. In other positions, gravity was used to maintain an open working corridor. When needed, additional working space was obtained by using suction tubes as mobile retractors.

\section{Neurophysiological Monitoring}

Electromyography monitoring of exposed $\mathrm{CNs}$ was used in all procedures. In recent years motor evoked potentials (MEPs) and compound muscle action potentials (CMAPs) were introduced and have become routinely used to monitor the corticospinal tract and the whole course of fibers involved in $\mathrm{CN}$ motor function. The facial nerve (CN VII, orbicularis oculi and oris muscles), trigeminal nerve (CN $\mathrm{V}$, masseter muscle), and accessory nerve (CN XI, trapezius muscle) were monitored in all procedures. Additional CNs (III-XII) were selectively chosen for monitoring. The choice of the CNs to be monitored was based upon the lesion location and the surgical approach. Muscles that were commonly monitored were the medial rectus for CN III, superior oblique for CN IV, lateral rectus for CN VI, and pharyngeal for CN IX, as well as the vocal cord by means of an electrode placed on the endotracheal tube for $\mathrm{CN}$ $\mathrm{X}$, and the tongue for CN XII. Brainstem auditory evoked potentials were also used to monitor CN VIII. MEPs were sampled by placing corkscrew stimulating electrodes on $\mathrm{C}-3$ and $\mathrm{C}-4$ and obtaining recordings from the abductor pollicis brevis and tibialis anterior muscles bilaterally. The same technique was used for facial corticobulbar MEPs to continuously assess the integrity of the facial nerve and nucleus (recording from the orbicularis oris muscle). SSEPs were also employed by stimulating the median and tibialis anterior nerves. This was performed to control the functional state of the spinothalamic pathways. Monitoring of the frontal cortex activity was also routinely conducted by the use of the bispectral index, which was performed in the anesthesiological setting along with electrocardiography continuous monitoring.

\section{Intraoperative and Postoperative Evaluation}

Any changes in neurophysiological and/or anesthesiological monitoring were recorded and retrospectively reviewed. In all patients a postoperative evaluation was conducted within the first postoperative day. This evaluation included a neurological examination and an axial CT brain scan. Before they were discharged, most of our patients underwent multiplanar MRI with contrast medium injection to grade the resection (as gross-total resection [GTR], subtotal resection [STR], or partial resection).

\section{Statistical Analysis}

Demographic and clinical data, surgical procedures, and outcomes were evaluated in all patients. The Wilcoxon signed-rank test was used to assess differences (reported as median values) between preoperative $\mathrm{mRS}$ and immediate postoperative $\mathrm{mRS}$ scores, and between preoperative mRS scores and postoperative mRS scores at 3 months. ${ }^{39}$ 


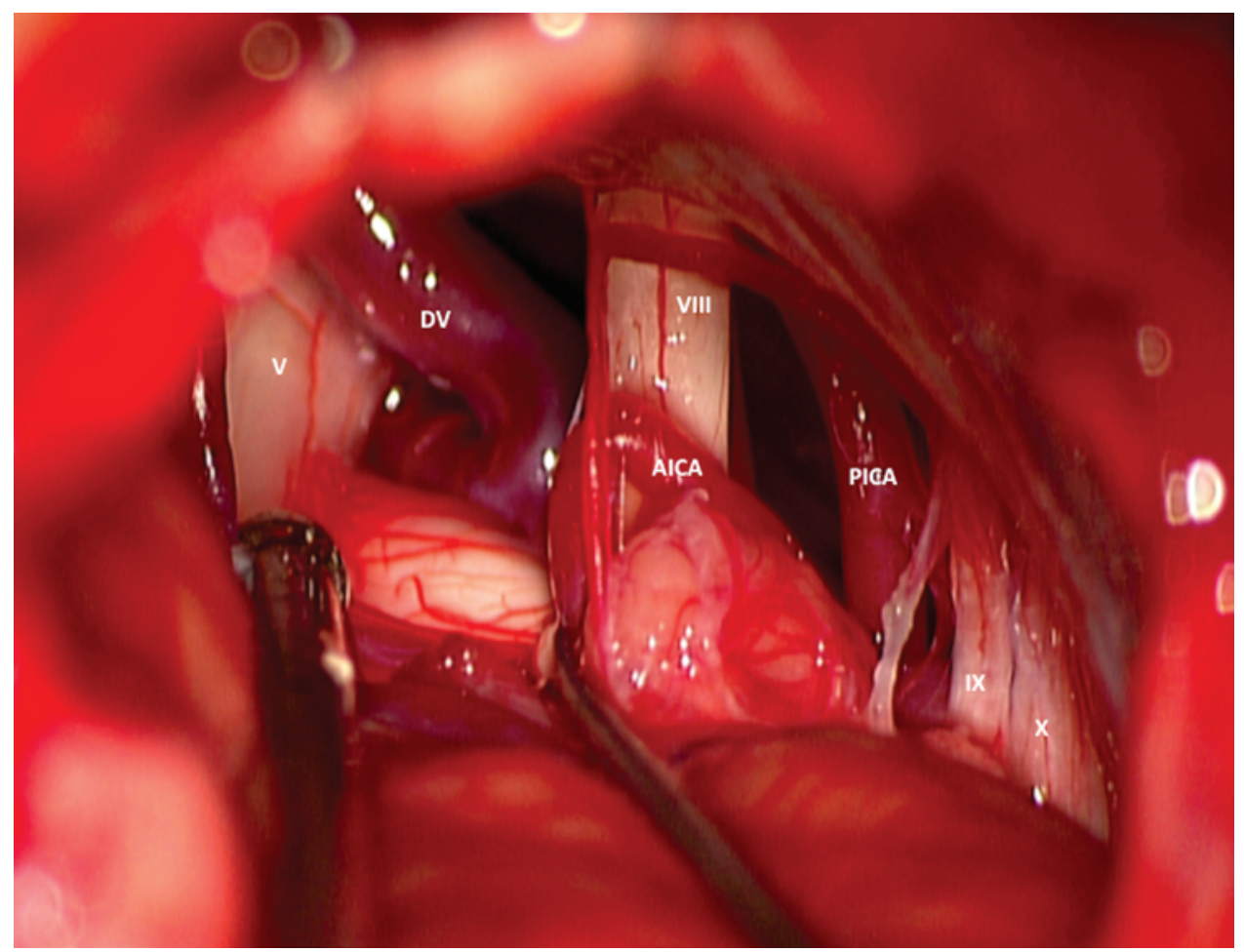

FIG. 4. Case 28. Intraoperative view of the right infratrigeminal lateral pontine window via a retrosigmoid approach. $V=$ trigeminal nerve; $\mathrm{VII}-\mathrm{VIII}$ = facial nerve-vestibular nerve complex (CN VII hidden by CN VIII); IX = glossopharyngeal nerve; $\mathrm{X}=$ vagus nerve; DV = Dandy's vein; AICA = anterior inferior cerebellar artery; PICA = posterior inferior cerebellar artery.

\section{Results}

The baseline clinical and surgical data of the 29 patients with deep pontine lesions in this study who underwent the lateral infratrigeminal transpontine approach are reported in Table 1. A simple biopsy procedure was performed in 4 patients. Lesion resection was graded as GTR in 19, STR in 4, and partial in 2 (Table 1). Any comparison among these different groups would not be significant due to the small sample size. We observed no deaths in this series. Surgical complications included 2 cases of hydrocephalus that required ventriculoperitoneal shunt placement, and 1 case of CSF leakage that was resolved after 5 days of spinal drainage. We observed no ischemic complications. In the immediate postoperative period, new neurological deficits were found to be present in $6(20.7 \%)$ of the 29 patients. All of these patients underwent lesion removal. Interestingly, during the surgical incision and during the approach to the deep lesions, we were not able to record any neurophysiological changes other than transient and brief low-frequency discharges of CN VII. Reversible arterial hypertension and bradycardia were found to occur on some occasions during this phase. We saw no evidence whatsoever of any intraoperative changes in SSEPs and MEPs during the transpontine surgical approach. During lesion dissections, however, we observed high-frequency electromyography firing discharges and a reduction in amplitude in facial corticobulbar MEPs and brainstem auditory evoked potentials. However, the amplitude of both of these signals never dropped below a level of $50 \%$ of the baseline. In most cases, we found that these alterations could be readily reversed by the interruption of surgical maneuvers.

From a clinical point of view, brainstem surgery through the infratrigeminal lateral window was not found to involve any immediate clinical worsening in 23 of the 29 patients studied. In six of the 29 patients, we believe that a manipulation injury of eloquent brainstem tissue during lesion removal was responsible for a patient's immediate postoperative worsening. We believe this because we saw no signs of any vascular arterial or venous lesions. The median $\mathrm{mRS}$ score in the immediate postoperative period was 3 , with scores ranging from 0 to 5 . The immediate postoperative $\mathrm{mRS}$ score compared with the preoperative mRS score revealed no statistically significant improvement $(p>0.05)$. In the weeks after surgery, any deficits that appeared to be related to deep lesion dissection were found to be generally improved. Only $7 \%$ of patients, or 2 of the 6 patients who showed any signs of postoperative clinical worsening, reported surgical sequelae 3 months after surgery. One of these patients had undergone glioblastoma resection and was severely disabled; the other patient had undergone a cavernoma resection and was moderately disabled (Table 1). Brainstem surgery through the infratrigeminal transpontine route yielded a definitive clinical improvement in $18(62 \%)$ of 29 patients, whereas $9(31 \%)$ remained unchanged. The median mRS score at 3 months was 2, with scores ranging from 0 to 5 . The comparison between 3-month postoperative mRS scores and preoperative mRS scores showed a statistically significant improvement (median 1, interquartile range $0-1$; $\mathrm{p}=0.002)$. 


\section{Illustrative Case of the Lateral Approach and Rationale}

\section{Presentation and Neurological Examination}

A 23-year-old man (Case 29, Table 1) presented with sudden brainstem impairment symptoms (diplopia, strabismus, dizziness, and left hemiparesis) 40 days before admission to our institution. A neurological examination revealed right $\mathrm{CN}$ VI-X deficits. Left hemiparesis with superficial hypoesthesia, ataxia, and left dysmetria were also observed.

\section{Imaging and Surgical Planning: the Decision-Making Process}

A CT scan showed a wide hemorrhagic area in the pons. An MR image with paramagnetic contrast (Gd) revealed a roundish lesion, hypointense on T2-weighted images, with a diameter of $2.3 \mathrm{~cm}$. The lesion involved the tegmental pontine area and was responsible for a distortion of the fourth ventricle without hydrocephalus (Fig. 5). Until this patient had been brought to our attention, his clinical status had been monitored elsewhere for the 40 days since the initial episode of bleeding, during which time he was able to remain fully awake without any new episodes of bleeding. During this period no improvement of any neurological deficits was observed. DTI-MR images were acquired to further evaluate the pontine anatomy (Fig. 1), and a 3D virtual planning workstation (Dextroscope) was used to enable the neurologists, neuroradiologists, and neurosurgeons to consider the positives and negative factors of both the posterior approach through the floor of the fourth ventricle and the lateral approach through the pontine transverse fibers and nuclei (Fig. 5). The following main topics listed below were considered and evaluated.

\section{Quality of Lesion Exposition and Working Corridor Offered by Each Approach}

For the dorsal route, which was considered a feasible option, the positive factors were a simple suboccipital midline standard craniotomy followed by a telovelar approach, and full exposition of the fourth ventricle floor without any vermian incision or excessive retraction. The negative factors were the need to make an incision of the velum of nervous tissue in the fourth ventricle floor that still covered the lesion, even though the function of this tissue has presumably already been damaged by the lesion (Fig. 5A and B). Also, the working corridor was not perfectly aligned with the major axis of the lesion, which would necessitate the retraction and repeated manipulation of the edges of the incision margins of the fourth ventricle floor to fully expose the lesion.

For the lateral route, which was considered the best option, the positive factors were that a translabyrinthine transapical approach provides a full exposition of the lateral pontine surface without any need for cerebellar retraction; the auditory function was already fully compromised; and the working trajectory offered by this approach is perfectly aligned with the main axis of the lesion (Fig. 5 C). The negative factor was that this approach is a longer transparenchymal route.
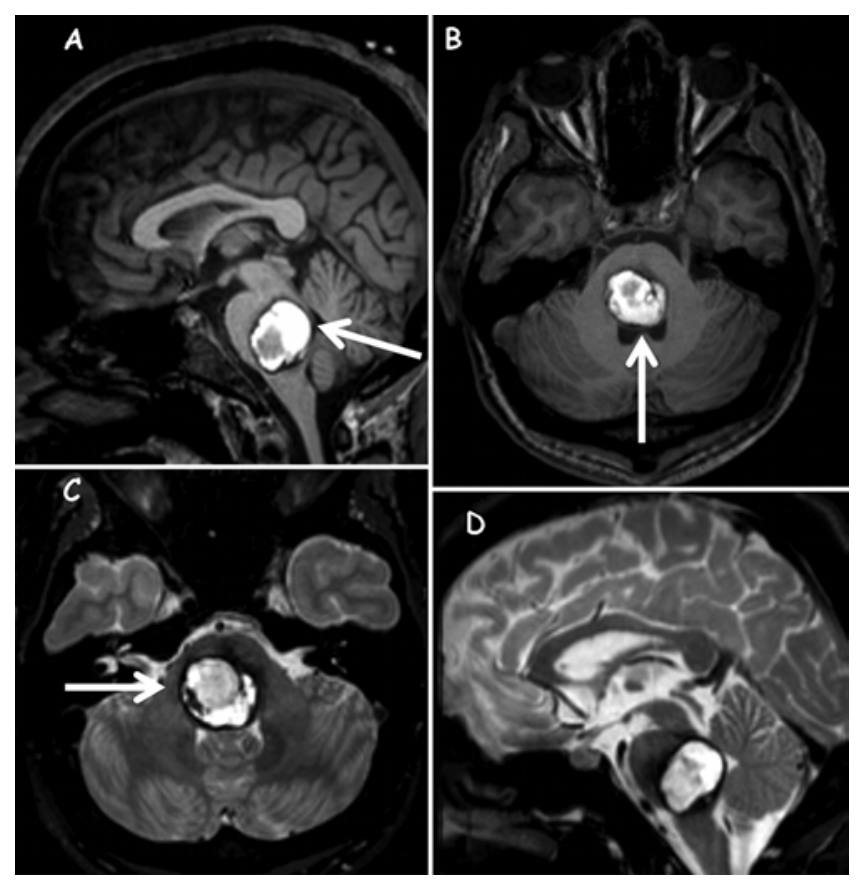

FIG. 5. Case 29. Sagittal (A) and axial (B) T1-weighted, and axial (C) and sagittal (D) T2-weighted MR images of a pontine cavernoma. Although the shortest path to the lesion is through the floor of the fourth ventricle (arrow in A and B illustrates a median suboccipital approach), a lateral approach $(\mathrm{C}$, arrow) is safer because it avoids motor fibers and $\mathrm{CN}$ nuclei.

\section{Risk of Complications Related to Each Approach}

The dorsal route was considered a low risk for complications, as CSF leakage and related infections, cerebellar injury, and postoperative hemorrhage and hydrocephalus are known to occur in less that $1 \%$ of cases with this approach in our experience. The risk of complications with the lateral route was considered as low as the dorsal route, in our experience.

\section{Risks of Neurological Sequelae Due to Retraction Injury of Eloquent Pontine Tissue}

The risk of neurological sequelae in the dorsal route was considered high due to the need for retraction of ventricle floor structures and to the lack of its full monitoring. However, this risk was considered low with the lateral route due to the expected tolerability of the lateral pontine region to surgical manipulation. Transverse pontine fibers are involved in the control of balance and coordination and are supposed to tolerate displacement much better than $\mathrm{CN}$ nuclei in the floor of the fourth ventricle.

The result of this decision-making process was that the operating surgeon (P.F.) considered both approaches feasible and good. However, his final decision favored the lateral approach because of a subjective feeling that it provided more significant safety.

\section{Postoperative Course}

After surgery, no new neurological deficits were observed. The patient's left hemiparesis and gait hemiparesis gradually improved. Dysphagia and dysphonia improved after focused physiotherapy. Postoperative MRI 
confirmed the total removal of the cavernous angioma (Fig. 6).

\section{Discussion}

Surgery of intraaxial brainstem lesions continues to remain a major challenge. In spite of many reports of promising results, the fact is that the question of surgical indications and ideal approaches continues to be part of an ongoing debate. Many factors such as age, neurological status, general clinical conditions of the patient, and the best treatment strategy for brainstem lesions are known to affect this debate. However, there is mounting evidence that shows that a policy of maximal safe resection is advisable for both tumors and vascular lesions because of clear correlations with better long-term outcomes. It is known that incomplete tumor removal carries a high risk of rebleeding in the case of cavernomas and a risk of short- and long-term complications (such as postoperative hemorrhage/residual tumor swelling, and disease progression) in the case of tumors. ${ }^{8,22,23,27,32}$ However, a complete removal should by no means be performed at the expense of unacceptable neurological deficits. Technical and technological advances in the last two decades have greatly contributed to the customization and management of the different surgical pathologies that can be located in the pons. Refinement of preoperative MRI with advanced techniques (mainly DTI, which provides a thorough topographical anatomical view of the nuclei and fasciculi of the crucial nerves), ${ }^{6,7,40}$ the introduction of virtual 3D surgical planning, ${ }^{11,12}$ fluorescence-guided surgery, ${ }^{1,35}$ and improved electrophysiological monitoring ${ }^{31}$ have all significantly combined to allow the surgeon to calibrate the surgery to the specific patient's anatomy and, in so doing, to reduce the impact of brainstem surgery on the patient's quality of life. These innovations, combined with a remarkable growth of interest in the neurosurgical community in this topic, have led to a reconsideration of the classic suboccipital posterior midline approach through the floor of the fourth ventricle and to an acceleration in the development of alternative multidisciplinary approaches to skull base techniques. The following is a list of skull base approach- es that have been described in the literature as effective means of removing brainstem lesions through different approaches: lateral perspective, retrosigmoid, retrolabyrinthine, translabyrinthine, transcochlear, anterior petrosectomy, far lateral transcondylar, subtemporal transtentorial, lateral supracerebellar infratentorial, and the anterior transpetrosal approach of Kawase. ${ }^{3-5,9,13,14,17,18,20,25,30,37}$

The recent widespread use of endoscopic transnasal techniques also facilitates anterior transclival approaches to resect brainstem lesions, ${ }^{19}$ but this approach does not appear suitable for deep lesions due to the ventral position of the corticospinal tract and the risk of vascular injury to the basilar artery and its branches. All of these approaches share the common aim of circumventing the need for a posterior brainstem incision. In fact, even though two low-morbidity posterior "entry zones" have been identified by Kyoshima et al. (i.e., the suprafacial and intrafacial trigones), the need for retracting and manipulating the margins of these "safe" incisions are easily followed by transient or permanent sequelae on the function of the eloquent surrounding structures (medial longitudinal fasciculus, CN V-X nuclei, etc.). ${ }^{20,31}$ The vulnerability of these structures is also revealed by neurophysiological monitoring, which when applied to this kind of surgery, may lead to aborting the procedure to avoid permanent neurological damage. ${ }^{29}$ Garret and Spetzler, in addressing the question of deep-seated lesions, have suggested that the surgeon must not only consider the shortest path from the surface to the lesion, but also the safest path. ${ }^{15}$ This particular consideration of path and safety has been the driving force underlying this study, and we have been extremely satisfied to discover that only $7 \%$ of patients described in this series have reported permanent surgical sequelae.

In this series, we elected to include and report on what we believe to be a somewhat provocative case involving brain structures deep in the pons. We have done so primarily because, even though it may have involved the longest path, this location could actually be considered "superficial" if it was approached through the floor of the fourth ventricle. We justify what may initially appear as a case of extreme avoidance behavior (of the fourth ventricle floor) by the fact that, after lesion debulking, the margins of the
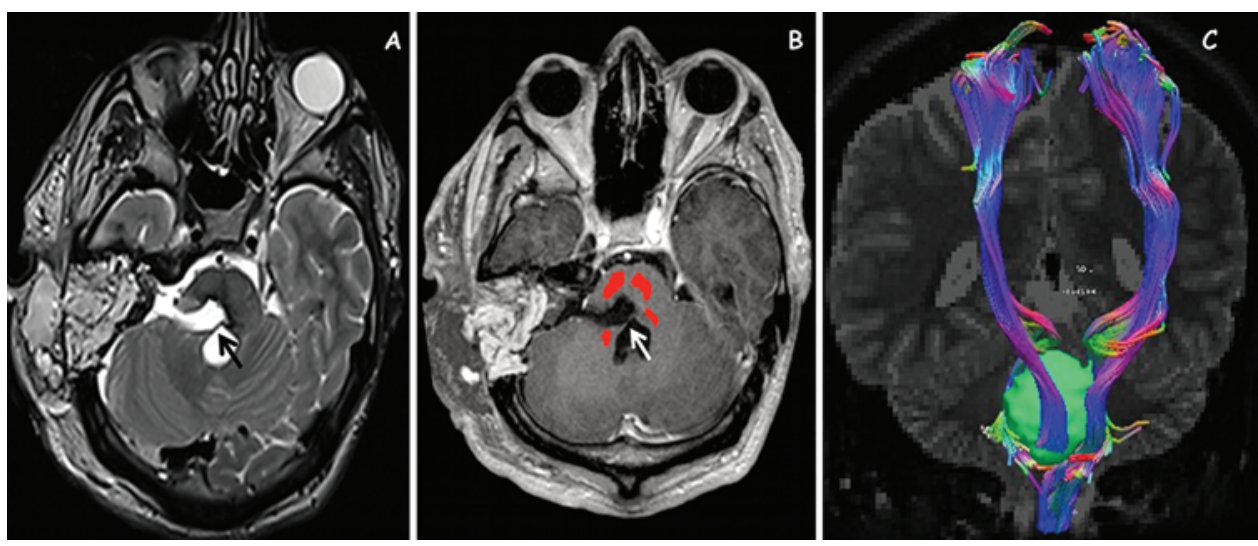

FIG. 6. Case 29. Postoperative axial MR images following a right translabyrinthine transapical approach. The floor of the fourth ventricle (arrow, $\mathrm{A}$ and $\mathrm{B}$ ) and the corticospinal tracts have been spared (B and $\mathrm{C}$ ). A: T2-weighted image. B: T1-weighted merged with fiber tractography (red). C: Fiber tractography of the corticospinal tracts. 
incision would have collapsed. In so doing, they would have hidden the deep portion of the lesion, thus requiring a complete resection that would have necessitated retracting these margins to keep the surgical corridor opened-and it was precisely that putative scenario that would have risked traumatizing the "unforgiving labyrinth" of nuclei and fibers (Fig. 7). We have great confidence that this risk can be minimized by an accurate and delicate surgical technique, with the aid of neurophysiological control, and that the route crossing the fourth ventricle is ideal for exophytic lesions that arise within the tegmental pontine region (as well as for purely tegmental lesions). We have, however, selected this particular case to emphasize how the use of lateral approaches can be progressively reinforced by positive prior institutional experience and by moving away from that time in our profession's history when the fourth ventricle was commonly chosen as a surgical route, to a time (today) when there is reason to believe it should be avoided whenever possible. Work completed by Cantore et al. (and supported by work done by Samii et al.) has emphasized that "The primary aim of surgery for cavernous angiomas of the pons is to preserve the anatomical and functional integrity of the nuclei of the VI and VII pairs of cranial nerves and of the medial longitudinal fasciculus," and Samii himself found that postsurgical lesions of the abducens and facial nerve nuclei showed a less satisfactory rate of spontaneous recovery. ${ }^{5,31}$

In our illustrative case, the surgical corridor could be maintained open with gentle traction on the transverse pontine fibers, ${ }^{25}$ and the manipulation of the tegmental pontine structures could then be limited to gentle countertraction along the cleavage plane of the cavernoma with respect to the whole fourth ventricle floor. The trio of findings all justify this attribute of "forgiving" that we have given to the infratrigeminal transpontine route: 1 ) width of the infratrigeminal lateral transpontine surgical corridor on postoperative MRI; 2) the absence of new immediate neurological deficits; and 3) a "good" level of autonomy experienced by the patient during the following months. In 1982, Baghai et al. was the first to describe this route as the safest corridor for taking biopsy samples of intrinsic pontine lesions. ${ }^{2}$ In the years since, many authors have been able to confirm the safety of this lateral route. . $1,17,25,29,30 \mathrm{In}$ our series as well, no morbidity was observed in the 4 patients who underwent biopsy.

The retrosigmoid approach appears to be the simplest route for exposing the infratrigeminal lateral pontine region, but its limited angle of vision may be problematic for some deep intrinsic lesions. Although the endoscope may assist with this problem, it is also true that the transpetrous approaches provide additional light toward the dorsal portion of deep pontine lesions. The two-point method introduced by Spetzler to help choose the approach for brainstem cavernomas appears to be the key to any discussion of alternative entry points and trajectories for each patient. ${ }^{26}$ In our experience, not only does the trajectory provided by the Spetzler two-point method work, but so, too, does the direction of the major axis of the lesion and the relative light provided by each different approach over the most delicate and dangerous dissection areas.

Despite the fact that the infratrigeminal transpontine route is known to exist, this series represents the first attempt to specifically focus on this brainstem entry point. In the present study, there were no deaths and $93 \%$ of the patients studied were found to be improved or remain relatively stable at the 3-month follow-up evaluation.

Additional deficits in the immediate postoperative period were found in $20 \%$ of patients. The 3-month postoperative outcome (evaluated using mRS scores) was found to be statistically significantly improved. In spite of the transpontine approach, most of our patients did not show any signs of neurological worsening or complications. When there were signs of worsening, we feel confident that this complication was not directly attributable to the transpontine route, but is much more likely attributable to the lesion dissection that was deep in the pons. Furthermore,
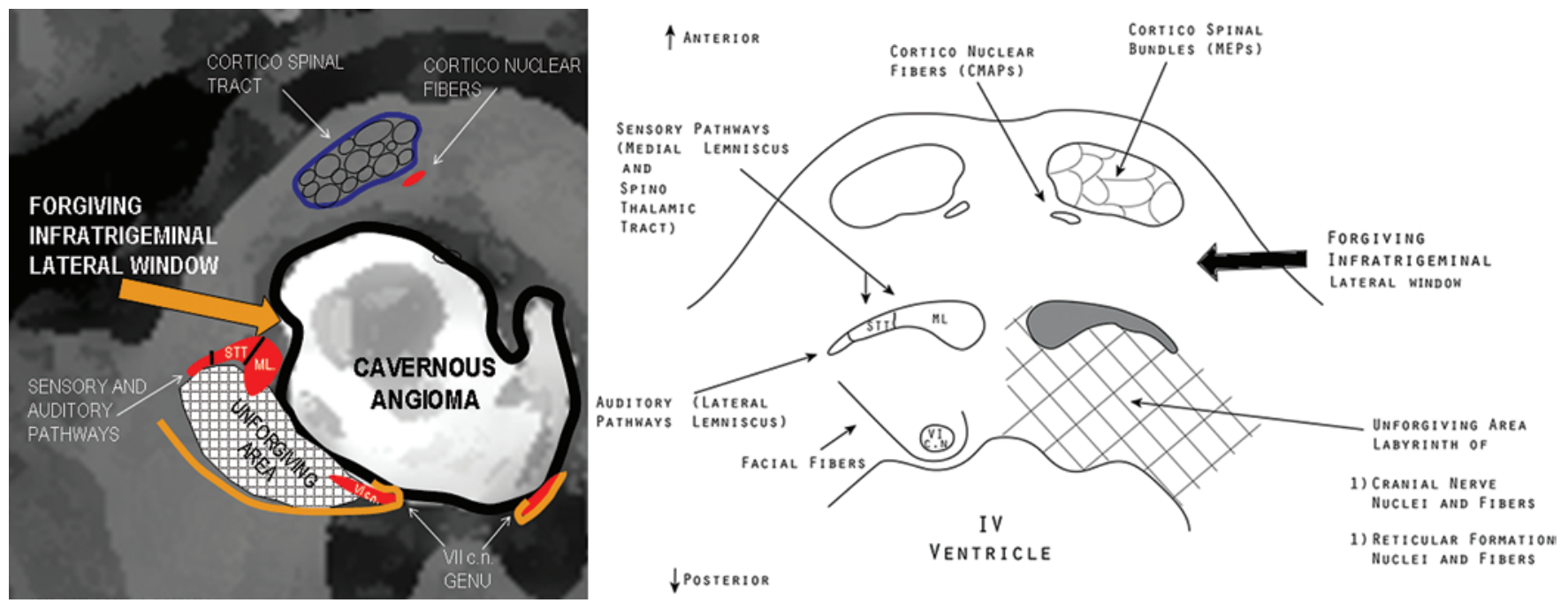

FIG. 7. Illustrative comparison of a mid-pons infratrigeminal pontine section with (left) and without (right) a lesion. The black arrow on the right and the orange arrow on the left show the surgical trajectory of the infratrigeminal transpontine approach behind the corticospinal tract and in front of the "unforgiving area." 
TABLE 2. Summary of baseline, surgical approach, and postoperative data

\begin{tabular}{|c|c|c|c|c|c|}
\hline Authors \& Year & $\begin{array}{l}\text { Patients w/ Pons Location } \\
\text { (Total Patients) }\end{array}$ & Pathology & Approach & $\begin{array}{l}\text { Long-term Morbidity } \\
\text { in Complete Series }\end{array}$ & Deaths \\
\hline Epstein \& McCleary, 1986 & $26(34)$ & $\mathrm{T}$ & Retrosigmoid, transventricular & 5 & 4 \\
\hline Zimmerman et al., 1991 & $5(16)$ & $\mathrm{CA}$ & $\begin{array}{l}\text { Transventricular, presigmoid, } \\
\text { subtemporal }\end{array}$ & 1 & 1 \\
\hline Bertalanffy et al., 1991 & $3(9)$ & $\mathrm{CA}$ & Retrosigmoid, transventricular & 1 & 0 \\
\hline Symon et al., 1991 & $4(7)$ & $\mathrm{CA}$ & Retrosigmoid, transventricular & 1 & 0 \\
\hline Cantore et al., 1999 & $5(12)$ & $\mathrm{CA}$ & Transventricular, presigmoid & 2 & 1 \\
\hline Porter et al., 1999 & $39(100)$ & $\mathrm{CA}$ & Retrosigmoid, presigmoid & $\begin{array}{l}8 \text { worse ( } 2 \text { in } 4 \text { th ven- } \\
\text { tricle approach) }\end{array}$ & $\begin{array}{l}3 \text { ( } 2 \text { in } 4 \text { th ven- } \\
\text { tricle approach) }\end{array}$ \\
\hline Sindou et al., 2000 & $8(12)$ & $\mathrm{CA}$ & Transventricular, retrosigmoid & 1 & 0 \\
\hline Samii et al., 2001 & $29(36)$ & $\mathrm{CA}$ & Presigmoid, transventricular & 22 & 0 \\
\hline Mathiesen et al., 2003 & $11(29)$ & $\mathrm{CA}$ & Transventricular & 4 (1 w/ pons location) & 1 \\
\hline Wang et al., 2003 & $90(137)$ & $\mathrm{CA}$ & Retrosigmoid, transventricular & 37 & 1 \\
\hline Gläsker et al., 2006 & $13(21)$ & $\mathrm{T}$ & Transventricular & 9 & 2 \\
\hline Garrett \& Spetzler, 2009 & Not available (86) & $\mathrm{CA}$ & Transventricular, retrosigmoid & 7 & 3 \\
\hline Ohue et al., 2010 & $22(36)$ & $\mathrm{CA}$ & $\begin{array}{l}\text { Transventricular, retrosigmoid, } \\
\text { presigmoid, middle fossa }\end{array}$ & 3 & 0 \\
\hline Hauck et al., 2010 & $9(9)$ & $\mathrm{CA}$ & Presigmoid & 1 & 0 \\
\hline Present series & $29(29)$ & $\mathrm{CA}, \mathrm{T}$ & Retrosigmoid, presigmoid & 2 & 0 \\
\hline
\end{tabular}

$\mathrm{CA}=$ cavernous angioma; $\mathrm{T}=$ tumor.

it should be noted that these deficits generally improved during follow-up, and only 2 patients $(6.9 \%)$ did not fully recover. These results compare well with the results of previous series (Table 2). . $, 5,8,15-17,21,24,26,31,33,36,38,41$ Differences in tumor location, dimension, histology, surgical technique, and grades of resection, along with the absence of a specific subgroup analysis in terms of different surgical approaches, make any comparison difficult. In addition, in our series the small sample size of each group of patients, where different grades of resection could be achieved, prevents further analysis and making definitive conclusions.

Despite the fact that our study appears to confirm the safety of the lateral infratrigeminal region as an avascular and neurologically low-risk route to the deep pons, we need to emphasize that there are some very real limitations related to the retrospective study design, the lack of a control group, the evolution of microsurgical and neurophysiological monitoring techniques over the 23 years of the study, and a selection bias possibly affecting this small series.

Recent advances in operative techniques and in the preservation of fundamental neural structures have created an exciting trend in our profession that will surely lead to greater surgical success. One of the results of this trend is that pontine surgery has been so greatly refined that it can now be considered to be a procedure with relatively low morbidity. However, this amount of success should not let us lose sight of the reality that brainstem surgery has not yet entered the land of evidence-based medicine, and that the expert opinion and decision-making capacity of the surgeon, replete with the limitations of human experience, remains a major factor when dealing with human lives.

\section{Conclusions}

Anatomical considerations and data coming from this retrospective study provide support to the idea that the lateral infratrigeminal transpontine route is a low-risk and safe corridor for either biopsy sampling or removal of deep pontine lesions.

\section{Acknowledgments}

We wish to thank to Prof. Allen Fertziger and Nicole Cuddeback for their invaluable help in transforming our Italian-English into a correct and understandable English with just some Latin flavors. We also wish to thank to Dr. Alessandra Solari for her help with the statistical analysis.

\section{References}

1. Acerbi F, Broggi M, Eoli M, Anghileri E, Cuppini L, Pollo B, et al: Fluorescein-guided surgery for grade IV gliomas with a dedicated filter on the surgical microscope: preliminary results in 12 cases. Acta Neurochir (Wien) 155:1277-1286, 2013

2. Baghai P, Vries JK, Bechtel PC: Retromastoid approach for biopsy of brain stem tumors. Neurosurgery 10:574-579, 1982

3. Bertalanffy H, Gilsbach JM, Eggert HR, Seeger W: Microsurgery of deep-seated cavernous angiomas: report of 26 cases. Acta Neurochir (Wien) 108:91-99, 1991

4. Bricolo A, Turazzi S: Surgery for gliomas and other mass lesions of the brainstem. Adv Tech Stand Neurosurg 22:261341,1995

5. Cantore G, Missori P, Santoro A: Cavernous angiomas of the brain stem. Intra-axial anatomical pitfalls and surgical strategies. Surg Neurol 52:84-94, 1999

6. Chen X, Weigel D, Ganslandt O, Buchfelder M, Nimsky C: Diffusion tensor imaging and white matter tractography in 
patients with brainstem lesions. Acta Neurochir (Wien) 149:1117-1131, 2007

7. Chen X, Weigel D, Ganslandt O, Fahlbusch R, Buchfelder M, Nimsky C: Diffusion tensor-based fiber tracking and intraoperative neuronavigation for the resection of a brainstem cavernous angioma. Surg Neurol 68:285-291, 2007

8. Epstein F, McCleary EL: Intrinsic brain-stem tumors of childhood: surgical indications. J Neurosurg 64:11-15, 1986

9. Fahlbusch R, Strauss C, Huk W: Pontine-mesencephalic cavernomas: indications for surgery and operative results. Acta Neurochir Suppl (Wien) 53:37-41, 1991

10. Ferroli P, Sinisi M, Franzini A, Giombini S, Solero CL, Broggi G: Brainstem cavernomas: long-term results of microsurgical resection in 52 patients. Neurosurgery 56:12031214,2005

11. Ferroli P, Tringali G, Acerbi F, Aquino D, Franzini A, Broggi G: Brain surgery in a stereoscopic virtual reality environment: a single institution's experience with 100 cases. Neurosurgery 67 (3 Suppl Operative):ons79-ons84, 2010

12. Ferroli P, Tringali G, Acerbi F, Schiariti M, Broggi M, Aquino D, et al: Advanced 3-dimensional planning in neurosurgery. Neurosurgery 72 (Suppl 1):54-62, 2013

13. François P, Ben Ismail M, Hamel O, Bataille B, Jan M, Velut $\mathrm{S}$ : Anterior transpetrosal and subtemporal transtentorial approaches for pontine cavernomas. Acta Neurochir (Wien) 152:1321-1329, 2010

14. Garber ST, Couldwell WT: Resection of an inferior pontine cavernous malformation using a far-lateral transcondylar approach. Acta Neurochir (Wien) 153:2461-2464, 2011

15. Garrett M, Spetzler RF: Surgical treatment of brainstem cavernous malformations. Surg Neurol 72 (Suppl 2):S3-S10, 2009

16. Gläsker S, Pechstein U, Vougioukas VI, Van Velthoven V: Monitoring motor function during resection of tumours in the lower brain stem and fourth ventricle. Childs Nerv Syst Oct 22:1288-1295, 2006

17. Hauck EF, Barnett SL, White JA, Samson D: The presigmoid approach to anterolateral pontine cavernomas. Clinical article. J Neurosurg 113:701-708, 2010

18. Hamilton MG, Wascher TM, Spetzler RF: Cavernous malformations of the brain stem, in Pasqualin A, Da Pian R (eds): New Trends in Management of Cerebro-Vascular Malformations. Vienna: Springer, 1994, pp 525-532

19. Kimball MM, Lewis SB, Werning JW, Mocco JD: Resection of a pontine cavernous malformation via an endoscopic endonasal approach: a case report. Neurosurgery 71 (1 Suppl Operative):186-194, 2012

20. Kyoshima K, Kobayashi S, Gibo H, Kuroyanagi T: A study of safe entry zones via the floor of the fourth ventricle for brain-stem lesions. Report of three cases. J Neurosurg 78:987-993, 1993

21. Mathiesen T, Edner G, Kihlström L: Deep and brainstem cavernomas: a consecutive 8-year series. J Neurosurg 99:3137, 2003

22. Miyamoto S, Mikuni N, Yamada K, Takahashi JA, Hashimoto N: Radical resection for intrinsic midbrain pilocytic astrocytoma: report of two cases. Acta Neurochir (Wien) 147:93-97, 2005

23. Nishikawa R: Standard therapy for glioblastoma-a review of where we are. Neurol Med Chir (Tokyo) 50:713-719, 2010

24. Ohue S, Fukushima T, Kumon Y, Ohnishi T, Friedman AH: Surgical management of brainstem cavernomas: selection of approaches and microsurgical techniques. Neurosurg Rev 33:315-324, 2010

25. Oiwa Y, Nakai K, Masaki Y, Masuo O, Kuwata T, Moriwaki $\mathrm{H}$, et al: Presigmoid approach for cavernous angioma in the pons-technical note. Neurol Med Chir (Tokyo) 42:91-98, 2002

26. Porter RW, Detwiler PW, Spetzler RF, Lawton MT, Baskin JJ,
Derksen PT, et al: Cavernous malformations of the brainstem: experience with 100 patients. J Neurosurg 90:50-58, 1999

27. Pozzati E, Acciarri N, Tognetti F, Marliani F, Giangaspero F: Growth, subsequent bleeding, and de novo appearance of cerebral cavernous angiomas. Neurosurgery 38:662-670, 1996

28. Rankin J: Cerebral vascular accidents in patients over the age of 60. II. Prognosis. Scott Med J 2:200-215, 1957

29. Recalde RJ, Figueiredo EG, de Oliveira E: Microsurgical anatomy of the safe entry zones on the anterolateral brainstem related to surgical approaches to cavernous malformations. Neurosurgery 62 (3 Suppl 1):9-17, 2008

30. Saito N, Sasaki T, Chikui E, Yuyama R, Kirino T: Anterior transpetrosal approach for pontine cavernous angioma-case report. Neurol Med Chir (Tokyo) 42:272-274, 2002

31. Samii M, Eghbal R, Carvalho GA, Matthies C: Surgical management of brainstem cavernomas. J Neurosurg 95:825-832, 2001

32. Simon M, Schramm J: Surgical management of intracranial gliomas. Recent Results Cancer Res 171:105-124, 2009

33. Sindou M, Yada J, Salord F: Functional results after microsurgical resection of brain stem cavernous malformations (retrospective study of a 12 patient series and review of the recent literature). Acta Neurochir (Wien) 142:843-853, 2000

34. Strauss C, Romstöck J, Nimsky C, Fahlbusch R: Intraoperative identification of motor areas of the rhomboid fossa using direct stimulation. J Neurosurg 79:393-399, 1993

35. Stummer W, Pichlmeier U, Meinel T, Wiestler OD, Zanella F, Reulen HJ: Fluorescence-guided surgery with 5-aminolevulinic acid for resection of malignant glioma: a randomised controlled multicentre phase III trial. Lancet Oncol 7:392401, 2006

36. Symon L, Jackowski A, Bills D: Surgical treatment of pontomedullary cavernomas. Br J Neurosurg 5:339-347, 1991

37. Vishteh AG, David CA, Marciano FF, Coscarella E, Spetzler RF: Extreme lateral supracerebellar infratentorial approach to the posterolateral mesencephalon: technique and clinical experience. Neurosurgery 46:384-389, 2000

38. Wang CC, Liu A, Zhang JT, Sun B, Zhao YL: Surgical management of brain-stem cavernous malformations: report of 137 cases. Surg Neurol 59:444-454, 2003

39. Wilcoxon F: Individual comparisons of grouped data by ranking methods. J Econ Entomol 39:269, 1946

40. Zausinger S, Yousry I, Brueckmann H, Schmid-Elsaesser $\mathrm{R}$, Tonn JC: Cavernous malformations of the brainstem: three-dimensional-constructive interference in steady-state magnetic resonance imaging for improvement of surgical approach and clinical results. Neurosurgery 58:322-330, 2006

41. Zimmerman RS, Spetzler RF, Lee KS, Zabramski JM, Hargraves RW: Cavernous malformations of the brain stem. J Neurosurg 75:32-39, 1991

\section{Author Contributions}

Conception and design: Schiariti, Ferroli, Cordella. Acquisition of data: Schiariti, Cordella, Boffano, Nava, La Corte, Claudio, Castiglione. Analysis and interpretation of data: Schiariti, Ferroli. Drafting the article: Schiariti, Ferroli, La Corte, Claudio, M Broggi. Critically revising the article: Acerbi, G Broggi. Reviewed submitted version of manuscript: Ferroli, Cordella, Boffano, Nava, La Corte, Claudio, Bauer, Castiglione, M Broggi, Acerbi, G Broggi. Approved the final version of the manuscript on behalf of all authors: Schiariti. Statistical analysis: Schiariti. Administrative/technical/material support: Castiglione. Study supervision: Ferroli, G Broggi.

\section{Correspondence}

Marco Paolo Schiariti, Department of Neurosurgery, Fondazione IRCCS Istituto Neurologico Carlo Besta, Via Celoria, 11, 20133, Milan, Italy. email: mp_schiariti@hotmail.com. 